\title{
The use of active coal feed supplement in the young fish feeding
}

\author{
K.S. Ostrenko ${ }^{1}$, N.A. Yurina ${ }^{2,3}$, E.V. Chernyshov ${ }^{2}$, A.N. Ovcharova ${ }^{1}$
}

\begin{abstract}
${ }^{1}$ All-Russia Research Institute of Animal Physiology, Biochemistry, and Nutrition, Branch of Ernst Russian Institute of Animal Breeding Federal Science Center for Animal Husbandry, Federal State Badgetary Scientific Institution (248010 Borovsk, p. Institute, Russian Federation); ${ }^{2}$ Krasnodar Research Center for Animal Husbandry and Veterinary Medicine, Krasnodar; ${ }^{3}$ Kuban State Agrarian University, Krasnodar, Russian Federation

*Corresponding author E-mail: Ostrenkoks@gmail.com,
\end{abstract}

Journal of Livestock Science (ISSN online 2277-6214) 12: 120-124

Received on 20/1/21; Accepted on 15/3/21; Published on 24/3/21

doi. 10.33259/JLivestSci.2021.120-124

\begin{abstract}
The aim of the study was to study the effect of feeding an active carbon feed additive (ACFS) on the biological fish-breeding indicators of young fish raised in closed reservoirs. The experiment was conducted in the conditions of the sturgeon farm "SOUTHERN CENTER of STURGEON BREEDING Latitude 46.686527, longitude 38.292442, Krasnodar Territory, Yeisk. The object of the study was the juvenile sturgeon of the ship. In the experiments, the traditional technology of keeping and feeding sturgeon fish with combined starter feeds in closed-loop installations was used. Analyzed the physico-chemical properties of water and the maintenance of chemical and toxic substances in feed sturgeon; the influence of the application of the feed ACF on biological indicators of fish, growth rate, survival rate, feed consumption, nutrient-dense foods and the coefficient of fatness of young sturgeon; the influence of application of active coal feed additives on the development of muscle tissue, chemical body composition of juvenile fish and the content of heavy metals. It is established that in the course of the experiment, all indicators of water in a closed water supply system was stable and consistent with existing requirements. It was found that the use of ACF in feeding young sturgeon fish contributes to an increase in their weight by $5.3-10.2 \%$, the fatness coefficient-by $1.7-7.5 \%$ and a reduction in feed costs for products-by $5.0-8.9 \%$. The use of ACFS has a positive effect on the development of muscle tissue, increasing the content of protein in it by $0.41-0.42 \%$, fat-by $0.16-0.32 \%$, and also reduces the content of heavy metals in the body of a young sturgeon by 1.5-2.0 times.
\end{abstract}

Key words: young sturgeon; compound feed; heavy metals; sorbent; fish mass; fatness coefficient 


\section{Introduction}

The Russian Federation has a state policy on priority development of fisheries in inland waters (Asanov, 2015, Sklyarov, 2015). Sturgeon production in the Krasnodar region has increased 12 times over the last five years and reached 250 tons per year. However, the industry needs to be developed, and economic and production indicators are reduced for a number of reasons (Sklyarov, 2015).

Sturgeons are fish species with biological and economic importance, and most of them are endangered, vulnerable or rare due to their large size, late sexual maturity, long period between spawning and longevity (Hao, 2018; Jafari, 2018).

Considering individual sectors of aquaculture, we note that, along with traditional technologies for growing commercial fish, the most important place is occupied by intensive forms of fish farming, in which the organization questions of full-fledged feeding is of paramount importance (Wang, 2016; Roy, 2018)

Improving the efficiency of the fish farming industry, along with solving technical problems, urgently requires the most serious attention to the feeding process and the use of cost-effective feed products for all age groups of bred fish (Doering, 2014; Krymov, 2018; Mugetti, 2020). The interest of scientists and practitioners in the use of new feed supplements, biologically active substances, including sorbents in the cultivation of fish, has been significantly increasing in recent years (Molina-Ruiz, 2015). The mechanism of their action is very extensive and, as many scientific experiments show, these new dietary supplements can be effective in a variety of animal husbandry industries, including fish farming. Moreover, it is not always possible to use compound feeds that meet all the requirements for safety indicators (Bakaneva, 2013; Silas, 2017; Yuan, 2019; Pshatsiyeva, 2019).

The purpose of the research was to study the effect of feeding an active coal feed supplement (ACFS) on biological fish-breeding indicators of young fish grown in closed water supply plants.

\section{Materials and methods}

The experiments were conducted in the conditions of sturgeon farm "SOUTHERN CENTER of STURGEON BREEDING Latitude 46.686527, longitude 38.292442, Krasnodar Territory, Yeisk. in fish-breeding pools of $4 \mathrm{~m} 3$ size with a stocking density of $18 \mathrm{pcs} / \mathrm{m} 2$. The water level in the pools was $0.5 \mathrm{~m}$. the object of research was juvenile ship sturgeon. There was used the traditional technology of keeping and feeding sturgeon fish with combined starter feeds in closed-cycle plants in the experiments. The experiments were conducted according to the "Methodological guide for the study of fish nutrition" (1974).

The fish feeding experiment was conducted according to the scheme presented in Table 1 . The duration of the second experiment was 40 days. Juveniles in the first (control) group obtained standard farm compound feed. In the experimental groups, the main diet was supplemented with the studied active coal feed supplement (ACFS) in the corresponding percentages with feed. Feeding was carried out 5 times a day with granulated feed mixtures.

Active coal feed supplement (ACFS) was produced in LLC scientific and technical Center "Himinvest", located in Nizhny Novgorod. The supplement is prepared from active charcoal with the addition of coniferous extract in an amount of at least $20 \%$ of the main mass. ACFS is intended to protect animals from the influence of feed and environmental toxicants, to produce environmentally friendly products and as sources of biologically active substances for the animal organism.

Feed for juvenile fish contained $13.19 \mathrm{MJ}$ of metabolic energy, $55.0 \%$ crude protein, $18.0 \%$ crude fat, $0.9 \%$ crude fiber, $2.2 \%$ lysine, $0.7 \%$ methionine, $1.1 \%$ methionine + cystine, $2.0 \%$ calcium, $1.7 \%$ phosphorus. Keeping conditions in all groups of fish were the same and corresponded to the technology of fish breeding. Young sturgeon fish weighing and body length measuring were carried out individually on electronic scales at the beginning and at the end of the experimental period. The gross and average daily increments were determined by periods. The length of the fish was measured from the top of the snout to the vertical end of the longest blade of the caudal fin when the fish was horizontal. Preservation (survival) was determined as a percentage of the surviving fish to the dead.

The fatness coefficient was determined as the ratio of mass to body length: according to the Fulton's formula (1) (fatness formula)

$$
\mathrm{K}=P \times 100 / L 3(1),(P / L 3) 100
$$

where $\mathrm{P}$ is the mass of the fish $(\mathrm{g})$ and $\mathrm{L}$ is the length of the body $(\mathrm{cm})$. Feed was fed manually. Accounting for the amount of feed consumed was individually for each group, according to the amount of the given feed and the leftover feed. Leftover feed was collected from containers by hand with a net, dried, and the mass was determined. The difference between the amount of introduced and uneaten feed was used to calculate the amount of feed intake (Sklyarov et al., 1984). Morphometric analysis of muscle tissue development was performed at the end of the experiment on 6 specimens from each group. The chemical composition of the fish body was determined using generally accepted methods of complete zootechnical analysis.

Table 1. Scheme of research and production experience $(n=100)$

\begin{tabular}{|l|l|}
\hline Groups & Feeding Characteristics \\
\hline 1 & Basic diet (BD) \\
\hline 2 & BD $+0.1 \%$ ACFS by feed weight \\
\hline 3 & BD $+0.2 \%$ ACFS by feed weight \\
\hline 4 & BD $+0.5 \%$ ACFS by feed weight \\
\hline
\end{tabular}




\section{Results and discussion}

During the research and production experiment, the water temperature in closed water supply plants was maintained at $+17 \pm 1,00 \mathrm{C}$. The optimal values of the hydrogen ion exponent for growing sturgeon fish ranged within the limits of 7.0-8.0. During the research and production experiment, the $\mathrm{pH}$ of water was 7.6.

All water indicators in the closed water supply plant during the scientific and economic experiment were stable and met the requirements of industry standart 15.312.87. " Nature protection. Hydrosphere. Water for fish farms. General requirements and rules" for the cultivation of sturgeon juveniles.

The main fish-breeding indicators for growing juvenile ship sturgeon are presented in Table 2.

The initial mass of fish when they were put in the pools was the same. However, there were significant differences at the end of the growing period. The final weight of the ship sturgeon increased significantly in the second group by $5.3 \%(\mathrm{P}<0.01)$, in the third - by $10.2 \%(\mathrm{P}<0.001)$, in the fourth-by $9.9 \%(\mathrm{P}<0.001)$.

Feed consumption in all groups was $251.2 \mathrm{~g}$ per 1 fish for the entire period of the experiment and was the same, because the feeding was normalized. However, feed costs per $1 \mathrm{~kg}$ of liveweight gain were lower in the experimental group. A decrease in feed costs per $1 \mathrm{~kg}$ of growth, compared with the control, was noted in the second group - by $5.0 \%$, in the third - by $9.5 \%$ and in the fourth - by $8.9 \%$.

The fatness coefficient of juvenile fish calculated by Fulton is shown in Table 3. The Fulton's fatness coefficient of sturgeon juveniles was higher in the second group of juveniles by $1.7 \%$, in the third - by $7.5 \%$, and in the fourth - by $3.3 \%$ compared to the control group. The obtained results allow us to conclude that the use of an active coal feed supplement (ACFS) in the feeding of ship sturgeon yearlings in a closed water supply system helps to increase its productivity.

At the end of the experimental period, a morphometric analysis of fish with a mass equal to the average for the group was performed (Table 4). It was established that in feeding young sturgeon fish with ACFS as part of fullfledged compound feeds, there is a tendency to increase the mass of fish carcasses by $0.5-1.1 \%$. There is a significant increase in the mass of fish muscle tissue - in the second group by $2.2 \mathrm{abs} . \%$, in the third-by 3.5 abs.\%, in the fourth-by $3.8 \mathrm{abs}$. \% (in all experimental groups $\mathrm{P}<0.001$ ). The weight of fish can increase due to the accumulation of reserve nutrients, so when conducting scientific and economic experiments to study the effectiveness of various feed additives, it is important to establish the relationship between the fatness coefficient and the protein and fat content in their body.

In the composition of fish tissues, the most important are proteins, fats, water and some minerals, in particular phosphorus and calcium. The chemical composition of the fish body was studied to justify the effectiveness of using an active coal feed supplement when growing young ship sturgeon in closed water supply plants (Table 5). According to the analysis of chemical body composition of juveniles a significant increase in protein content in the fish body third group $-0.42 \mathrm{abs} . \%$, the fourth group $-0.41 \mathrm{abs} . \%(\mathrm{P}<0.05)$ was established. In all experimental groups, the mass fraction of fat increased significantly $(\mathrm{P}<0.05)$, which is consistent with the data on an increase in fish mass and the Fulton's fatness coefficient: in the second group - by 0.32 abs. $\%$, in the third by $0.20 \mathrm{abs} . \%$, in the fourth - by $0.16 \mathrm{abs} . \%$. There was a positive trend towards a decrease in the moisture content in the body of fish of the experimental groups and an increase in the ash, calcium and phosphorus content, but based on these data, it can be said that ACFS does not remove minerals from the body.

Data on the content of heavy metals in the homogenate of the body of juvenile ship sturgeon are presented in Table 6. The research results showed that feeding the ACFS sorbent significantly reduces the content of heavy metals in the body of young sturgeon by 1.5-2.5 times ( $\mathrm{P}<0.001$ in the third and fourth groups).

Thus, the results of the experiment showed that the use of ACFS sorbent in mixed feeds for young ship sturgeon has a positive effect on the productivity and quality of fish meat. It was found that at a certain level of heavy metal content in feed, feeding ACFS significantly reduces the level of residual quantity of cadmium, mercury and lead in the body of fish.

The results obtained in the course of the study are consistent with the results of international studies in the field of fish production. Amin Mojiri, that in the Karun River in Iran (1.21 $\times 105 \mathrm{ng} / \mathrm{1})$, the concentration of pesticides exceeds the regulatory limits. The concentration of pesticides in fish can reach $26.1 \times 103$ micrograms $/$ $\mathrm{kg}$, in particular the herbicide methoxychlor in Perca fluviatilis in Lithuania. In recent years, research has focused on eliminating organic pollutants, such as pesticides, from aqueous solutions. The adsorption of pesticides on inexpensive materials can effectively reclaim polluted waters. In particular, nanoparticle-based adsorbents and carbon adsorbents demonstrate high efficiency (almost 100\%) in removing pesticides from water bodies (Mojiri, 2020). The development of new desorbents is a modern approach to obtaining an ecological product, which is confirmed by the work of Han L. and co-authors. In their work, they used a new carbon / zirconium-based material SupelTM QuE Verde was evaluated in a filter bottle of dispersion solid-phase extraction purification of pork, salmon, cabbage and avocado extracts for the residual analysis of 65 pesticides and 52 environmental pollutants (flame retardants, polychlorinated biphenyls, polybrominated biphenyl esters and polycyclic aromatic hydrocarbons) using low-pressure gas chromatography with tandem mass transfer.spectrometry. The addition of Verde to the primary secondary amine and C18 during purification resulted in an increase in the removal of gas chromatographic co-extractives by $38 \%$ in avocado, $30 \%$ in cabbage, $39 \%$ in salmon, and $50 \%$ in pork. The removal efficiency of coextracted chlorophyll was $93 \%$ for cabbage and $64 \%$ for avocado based on UV-visible absorption (Han L, 2016). 
Table 2. Main fish-breeding indicators for growing sturgeon juveniles $(\mathrm{n}=100)$

\begin{tabular}{|c|c|c|c|c|}
\hline \multirow{2}{*}{ Indicators } & \multicolumn{4}{|l|}{ Group } \\
\hline & 1 & 2 & 3 & 4 \\
\hline Average fish weight. g: initial & $220.0 \pm 2.3$ & $220.0 \pm 1.7$ & $220 \pm 2$ & $220 \pm 2$ \\
\hline final & $360.3 \pm 4.1$ & $379.3 \pm 4.0^{* *}$ & $396.9 \pm 4.3 * * *$ & $396.0 \pm 4.8 * * *$ \\
\hline as $\%$ of control & 100.0 & 105.3 & 110.2 & 109.9 \\
\hline Growth rate (average daily growth). g & 3.5 & 4.0 & 4.4 & 4.4 \\
\hline Survival rate. $\%$ & 100 & 100 & 100 & 100 \\
\hline \multicolumn{5}{|l|}{ For $1 \mathrm{~kg}$ of growth it was spent: } \\
\hline feed. $\mathrm{kg}$ & 1.79 & 1.70 & 1.62 & 1.63 \\
\hline as $\%$ of control & 100.0 & 95.0 & 90.5 & 91.1 \\
\hline
\end{tabular}

$* \mathrm{P}<0.05 ; * * \mathrm{P}<0.01 ; * * * \mathrm{P}<0.001$ according to the $\mathrm{t}$-criterion when compared with the control.

Table 3. Fatness coefficient of juvenile fish

\begin{tabular}{|l|l|l|l|l|}
\hline \multirow{2}{*}{\multicolumn{1}{|c|}{ Indicators }} & \multicolumn{3}{c|}{ Group } \\
\cline { 2 - 5 } & \multicolumn{1}{c|}{1} & \multicolumn{1}{c|}{2} & \multicolumn{1}{c|}{3} \\
\hline Fish length. cm & $24.7 \pm 0.29$ & $25.0 \pm 0.40$ & $24.9 \pm 0.20$ & $25.2 \pm 0.24$ \\
\hline Fatness by Fulton & 2.39 & 2.43 & 2.57 & 2.47 \\
\hline As \% of the control & 100.0 & 101.7 & 107.5 & 103.3 \\
\hline
\end{tabular}

Table 4. The results of morphometric analysis of juvenile fish $(n=6)$

\begin{tabular}{|l|l|l|l|l|}
\hline \multirow{2}{*}{ Indicators } & \multicolumn{3}{|c|}{ Group } & \multicolumn{1}{|c|}{3} \\
\cline { 2 - 5 } & \multicolumn{1}{|c|}{1} & \multicolumn{1}{|c|}{2} & \multicolumn{1}{|c|}{4} \\
\hline Fish weight. g & $359.7 \pm 6.2$ & $397.8 \pm 6.0^{* * *}$ & $395.1 \pm 5.2^{* * *}$ & $396.0 \pm 4.3_{* *}$ \\
\hline $\begin{array}{l}\text { Weight of gutted carcass (with head and } \\
\text { fins). g }\end{array}$ & $325.2 \pm 5.4$ & $364.0 \pm 4.7 * *$ & $360.7 \pm 5.4 * *$ & $360.0 \pm 7.3 *$ \\
\hline As \% of the initial mass & 90.4 & 91.5 & 91.3 & 90.9 \\
\hline $\begin{array}{l}\text { Weight. g: } \\
\text { head and fins. g }\end{array}$ & $116.4 \pm 3.0$ & $127.0 \pm 3.2$ & $122.3 \pm 2.6$ & $124.2 \pm 2.2^{*}$ \\
\hline as \% of weight of gutted carcass & 35.8 & 34.9 & 33.9 & 34.5 \\
\hline skin & $40.7 \pm 0.5$ & $41.1 \pm 0.4$ & $42.2 \pm 0.3$ & $41.4 \pm 0.3$ \\
\hline as \% of weight of gutted carcass & 12.5 & 11.3 & 11.7 & 11.5 \\
\hline cartilaginous tissue & $29.9 \pm 0.3$ & $32.8 \pm 0.5 * *$ & $32.1 \pm 0.6 *$ & $30.6 \pm 0.7$ \\
\hline as \% of weight of gutted carcass & 9.2 & 9.0 & 8.9 & 8.5 \\
\hline muscle tissue & $136.3 \pm 3.3$ & $160.5 \pm 2.2^{* * *}$ & $163.8 \pm 2.1 * * *$ & $163.1 \pm 2.0^{* * *}$ \\
\hline as \% of weight of gutted carcass & 41.9 & 44.1 & 45.0 & 45.3 \\
\hline
\end{tabular}

$* \mathrm{P}<0.05 ; * * \mathrm{P}<0.01 ; * * * \mathrm{P}<0.001$ according to the $\mathrm{t}$-criterion when compared with the control.

Table 5. Chemical composition of the body of juvenile fish ( $\mathrm{n}=6$ )

\begin{tabular}{|l|l|l|l|l|}
\hline \multirow{2}{*}{ Indicators } & \multicolumn{3}{|c|}{ Group } & \multicolumn{1}{c|}{3} \\
\cline { 2 - 5 } & \multicolumn{1}{|c|}{1} & \multicolumn{1}{|c|}{2} & \multicolumn{1}{c|}{4} \\
\hline Moisture. \% & $83.06 \pm 0.18$ & $82.39 \pm 0.07$ & $82.42 \pm 0.17$ & $82.45 \pm 0.10$ \\
\hline Protein. \% & $10.94 \pm 0.15$ & $11.26 \pm 0.05$ & $11.36 \pm 0.04^{*}$ & $11.35 \pm 0.07^{*}$ \\
\hline Fat. \% & $3.94 \pm 0.05$ & $4.26 \pm 0.08^{*}$ & $4.14 \pm 0.04^{*}$ & $4.10 \pm 0.03^{*}$ \\
\hline Ash. \% & $2.07 \pm 0.03$ & $2.1 \pm 0.04$ & $2.09 \pm 0.01$ & $2.1 \pm 0.05$ \\
\hline Calcium. g/kg & $4.55 \pm 0.07$ & $4.94 \pm 0.35$ & $4.57 \pm 0.05$ & $4.56 \pm 0.07$ \\
\hline Phosphorus. g/ kg & $3.37 \pm 0.11$ & $3.44 \pm 0.11$ & $3.45 \pm 0.11$ & $3.41 \pm 0.05$ \\
\hline
\end{tabular}

$* \mathrm{P}<0.05$. according to the t-criterion when compared with the control.

Table 6. Content of heavy metals in the ship sturgeon body homogenate ( $\mathrm{mg} / \mathrm{kg} . \mathrm{n}=6$ )

\begin{tabular}{|l|l|l|l|l|}
\hline \multirow{2}{*}{ Indicators } & \multicolumn{3}{|c|}{ Group } \\
\cline { 2 - 5 } & \multicolumn{1}{|c|}{1} & \multicolumn{1}{|c|}{2} & \multicolumn{1}{|c|}{3} \\
\hline Dosage of ACFS & - & 0.1 & 0.2 & 0.5 \\
\hline Cadmium (MPC 0.2) & $0.03 \pm 0.001$ & $0.02 \pm 0.001 * * *$ & $0.01 \pm 0.001 * * *$ & $0.01 \pm 0.001 * * *$ \\
\hline Mercury (MPC 0.5) & $0.20 \pm 0.001$ & $0.17 \pm 0.006$ & $0.11 \pm 0.005 * *$ & $0.10 \pm 0.001^{*} * *$ \\
\hline Lead (MPC 1.0) & $0.05 \pm 0.004$ & $0.05 \pm 0.002$ & $0.02 \pm 0.001 * * *$ & $0.02 \pm 0.006 * * *$ \\
\hline
\end{tabular}

$* \mathrm{P}<0.05 ; * * \mathrm{P}<0.01 ; * * * \mathrm{P}<0.001$ according to the $\mathrm{t}$-criterion when compared with the control.

\section{Conclusion}

The research of the biological fish-breeding indicators of juvenile sturgeon when feeding feed supplements with sorption properties allows to conclude that during the experiment in a recirculating aquacultural system in which all water parameters were stable and met the requirements of the industry standard 15.312.87, the application of ACFS in feeding sturgeon young fish contributes to growth intensity, coefficient of fatness, reducing feed cost of production, increasing muscular tissue mass and improving its chemical composition, reduces the content of heavy metals in the body of young sturgeon by 1.5-2.0 times. 


\section{References}

1) Asanov A.Yu., SklyarovV.Ya. (2015) [Prospects for the use of water bodies of complex purpose of the Penza region for aquaculture]. Trudy Kubanskogo GAU - Proc. Kuban State Agric. Univ. 2015, 56: 61-68. (In Russian)

2) Bakaneva Yu.M., Bychkova A.P., Bakanev N.M., FedorovykhYu.V. 2013. [Use of zeolites in sturgeon feed].VestnikAstrakhanskogogosudarstvennogotekhnologicheskogouniversiteta - Bulletin of the Astrakhan State Technological University.2013, 5: 28-34. (In Russian)

3) Doering J.A., Wiseman S., Beitel S.C., Giesy J.P., Hecker M. 2014. Identification and expression of aryl hydrocarbon receptors (AhR1 and AhR2) provide insight in an evolutionary context regarding sensitivity of white sturgeon (Acipensertransmontanus) to dioxin-like compounds. Aquatic Toxicology. 150: 27-35. DOI: 10.1016/j.aquatox.2014.02.009.

4) Han L, Sapozhnikova Y, Matarrita J. 2016. Evaluation of a new carbon/zirconia-based sorbent for the cleanup of food extracts in multiclass analysis of pesticides and environmental contaminants. Journal of Separation Science. 39(23) :4592-4602. DOI: 10.1002/jssc.201600920.

5) Hao J., Liu Q., Zhang X., Wu Y., Zhu J., Qi J., Tang N., Wang S., Wang H., Chen D., Li Z. 2017. The evidence of apelin has the bidirectional effects on feeding regulation in Siberian sturgeon (Acipenserbaerii). Peptides. 94: 78-85. DOI: 10.1016/j.peptides.2017.05.007.

6) Jafari N., Falahatkar B., Sajjadi M.M. 2018. Growth performance and plasma metabolites in juvenile Siberian sturgeon Acipenserbaerii (Brandt, 1869) subjected to various feeding strategies at different sizes. Fish Physiology and Biochemistry. 44(5): 1363-1374. DOI: 10.1007/s10695-018-0527-8.

7) Krymov V.G., Yurin D.A., Kononenko S.I., Maxim E.A., Yurina N.A. 2018. changes of weight indicators in sturgeon fish when using combined feeds with various protein and fat contents in closed water supply installations. International Journal of Pharmaceutics. 10(4): 316-322.

8) Major A, Zhou JL, Robinson B, Ohashi A, Ozaki N, Kindaichi T, Farraji H, Vakili M. 2020. Pesticides in aquatic environments and their removal by adsorption methods. Chemosphere. 253:126646. DOI: 10.1016/j.chemosphere.2020.126646.

9) Molina-Ruiz J.M., CieslikE., CieslikI. 2015. WalkowskaI.Determination of pesticide residues in fish tissues by modified QuEChERS method and dual-d-SPE clean-up coupled to gas chromatography-mass spectrometry. Environmental Science and Pollution Research. 22(1):369-78. DOI: 10.1007/s11356-014-3361-2.

10) Mugetti D, Pastorino P, Menconi V, Pedron C, Prearo M. 2020. The old and the new on viral diseases in sturgeon. Pathogens. 9(2): 146. DOI: 10.3390/pathogens9020146

11) Pshatsiyeva Z.V., Yurina N.A., Khorin B.V., Labutina N.D., Danilova A.A., Ustyuzhaninova T.A. 2019. Studying the efficiency of natural and synthetic adsorbents in combined feed for broiler chickens. Advances in Animal and Veterinary Sciences., 7(Special Issue 1): 1-5.

12) Roy N.K., DellaTorre M., Candelmo A., Chambers R.C., Habeck E., Wirgin I. 2018. Characterization of AHR1 and its functional activity in Atlantic sturgeon and shortnose sturgeon. Aquatic Toxicology. 205: 25-35. DOI: 10.1016/j.aquatox.2018.09.014.

13) Silas S.O. 2017. Recent advances in sturgeon nutrition. Animal Nutrition. 3(3): 191-204. DOI: 10.1016/j.aninu.2017.05.005.

14) Sklyarov V.Ya. 2015 [Scientific support, reserves for the development of aquaculture in the South of Russia]. Rybnoe khozyaistvo - Fish Industry. 5: 55-60. (In Russian)

15) Sklyarov V.Ya., Bondarenko L.G, KovalenkoYu.I., Petrashov V.I., Kashirin A.V., Chernykh E.N. 2015 [Prospects for the development of aquaculture in the South of Russia]. Rybovodstvo i rybnoe khozyaistvo Fish Industry and Fish Farming., 9: 3-8. (In Russian)

16) Wang W., Lee S., Hung S.S.O., Deng D.F. 2016. Responses of heat shock protein 70 and caspase-3/7 to dietary selenomethionine in juvenile white sturgeon. Animal Nutrition. 2(1):45-50. DOI: 10.1016/j.aninu.2016.02.001.

17) Yuan L., Li L., Zhang X., Jiang H., Chen J. 2019. Identification and differential expression of piRNAs in the gonads of Amur sturgeon (Acipenserschrenckii). Peer J. 7: e6709. DOI: 10.7717/peerj.6709. eCollection 2019. 